\title{
Contaminação por Aspergillus flavus e A. fumigatus em sementes de girassol (Helianthus annuus) utilizados na alimentação de psitacídeos
}

\author{
Alexsandro Machado Conceição ${ }^{1 *}$ \\ Clênio Bezerra Melo \\ Carlos Alberto Palmeira Sarmento ${ }^{3}$ \\ ${ }^{1}$ Rua Construtor João Alves, 72, CEP 49020-340 - Aracaju - SE, Brasil \\ ${ }^{2}$ Laboratório de Microbiologia, Faculdade Pio Décimo, Aracaju - SE, Brasil \\ ${ }^{3} \mathrm{PPG}$ em Anatomia dos Animais Domésticos e Silvestres \\ Faculdade de Medicina Veterinária e Zootecnia, Universidade de São Paulo \\ São Paulo - SP, Brasil \\ *Autor para correspondência \\ alexmedvet@hotmail.com
}

Submetido em 01/11/2009

Aceito para publicação em 15/03/2010

\section{Resumo}

Amplamente difundido na alimentação de psitacídeos em razão do preço baixo, elevada palatabilidade, e por razões culturais, o Helianthus annuus, conhecido como girassol, vem se mostrando importante na clínica aviária em decorrência do excesso de calorias, e da alta incidência na contaminação por alguns fungos, principalmente do gênero Aspergillus, especificamente A. flavus e A. fumigatus. O objetivo deste estudo foi avaliar a contaminação por Aspegillus ssp. em sementes de girassol destinada à alimentação de psitacídeos comercializadas em Aracaju, estado de Sergipe. As análises foram realizadas no Laboratório de Microbiologia, do Hospital Veterinário Dr. Vicente Borreli, na Faculdade Pio Décimo. Avaliaram-se quatro amostras de sementes de girassol, sendo uma comercializada no mercado público municipal, de forma granel e três marcas comerciais, envasadas e de diferentes hipermercados, processadas segundo Forsythe (2002). De acordo com a pesquisa realizada, foi possível observar um elevado desenvolvimento de $A$. flavus e A. fumigatus nas sementes de girassol. Esta contaminação pode estar relacionada a vários fatores: colheita e fases de secagem, beneficiamento e armazenamento do grão inadequado. Além disso, é importante destacar a necessidade de que haja um melhor armazenamento de grãos, com controle de temperatura e umidade relativa, visando reduzir a possibilidade de contaminação por Aspergillus spp. que causa prejuízos na alimentação de psitacídeos, e de outras espécies animais.

Unitermos: Aspergillus flavus, Aspergillus fumigatus, Helianthus annuus

\section{Abstract}

Contamination by Aspergillus flavus and A. fumigatus in sunflower seeds used in psittacine bird food. Widely distributed in food for psittacine birds due its low price, high palatability, and cultural reasons, the Helianthus annuus, called sunflower, is proving important in clinical influenza as a result of excess calories and high incidence of contamination by some fungi, particularly Aspergillus, specifically A. flavus and A. fumigatus. The aim of this study was to evaluate the contamination by Aspergillus spp sunflower seeds for feeding psittacine 
birds, sold in Aracaju, Sergipe state. The tests were performed in the Laboratory of Microbiology of the Dr. Vicente Borreli Veterinary Hospital in Pio Décimo College. We evaluated four samples of sunflower seeds, sold in a municipal market and in three different supermarkets in bulk and under three bottled trademarks, processed according to Forsythe (2002). Our survey revealed a high development of $A$. flavus and A. fumigatus sunflower seeds. This contamination may be related to several factors such as inadequate harvest stages of drying, processing and storage of grain. Furthermore, it is important to highlight the need of a better grain storage, with controlled temperature and humidity, to reduce the possibility of contamination by Aspergillus spp. that causes injury in the feeding of psittacine birds and other animal species.

Key words: Aspergillus flavus, Aspergillus fumigatus, Helianthus annuus

\section{Introdução}

O Helianthus annuus, vulgarmente conhecido como girassol, é largamente difundido na alimentação de psitacídeos em razão do baixo preço, da elevada palatabilidade e do valor nutritivo. No entanto, o mesmo vem se mostrando de grande importância na clínica aviária, em decorrência do excesso de calorias, além de apresentar contaminação por alguns fungos, principalmente do gênero Aspergillus, especificamente pelas espécies $A$. flavus $\mathrm{e}$ A. fumigatus que, por produzirem toxinas (aflatoxinas), tornam-se uma das principais causas de intoxicações observadas na medicina aviária (Junior, 2001). Estas toxinas são termoestáveis, ou seja, não são destruídas por nenhuma forma de calor, e não existem antídotos para elas (Lavor e Souza, 2008).

De acordo com Tanaka et al. (2001) e Diniz (2002) o desenvolvimento e a formação das aflatoxinas em alimentos são dependentes de uma série de fatores, principalmente daqueles relacionados à umidade maior que $85 \%$, temperatura entre $8^{\circ} \mathrm{C}$ e $42^{\circ} \mathrm{C}$, presença de oxigênio e à constituição do substrato. $\mathrm{O}$ acúmulo desta toxina no organismo da ave depende da dose e da frequência com que é ingerida. Para sua desintoxicação, a ave demora em torno de quatro meses para eliminar todas as micotoxinas (Benez, 2001).

A aspergilose é uma doença secundária favorecida por debilidade, imunodepressão e por manejo inadequado. Pode apresentar duas formas distintas: aguda e crônica. A forma aguda é induzida pela inalação de grande concentração de conídios e caracterizada por severos surtos de mortalidade e morbidade, principalmente, em aves jovens. A forma crônica é a forma clássica da enfermidade, incide normalmente nas aves mais velhas apresentando um curso clínico de semanas a meses, induzida por condições de imunossupressão (Richard, 1997; Tovar, 1999). É predominantemente uma doença respiratória, mas pode apresentar uma forma ocular, nervosa, e com menos frequência à forma cutânea (Campbell, 1986; Andreatti Filho, 2006).

O objetivo deste estudo foi avaliar a contaminação por Aspegillus ssp. em sementes de girassol comercializadas em Aracaju, estado de Sergipe, destinada à alimentação de psitacídeos.

\section{Material e Métodos}

O experimento foi realizado no Laboratório de Microbiologia, do Hospital Veterinário Dr. Vicente Borreli, na Faculdade Pio Décimo, Aracaju, Sergipe no período de Março a Junho de 2005. Foram utilizadas quatro amostras de sementes de girassol, sendo uma comercializada no mercado público municipal, de forma granel, armazenadas em caixas de madeira com tampa e expostos ao ambiente de comercialização, e três de marcas comerciais, envasadas e de diferentes hipermercados.

O material de coleta foi processado segundo Forsythe (2002), onde foram homogeneizados grãos utilizando um Stomacher, (modelo BOIT-STO1). As amostras foram pesadas, $25 \mathrm{~g}$ cada e diluídas em $225 \mathrm{ml}$ de água peptonada a 1:10. O pré-enriquecimento foi realizado para obter a recuperação das células lesadas.

Após agitação da mistura, foi preparada a partir desta, diluições de $10^{-2}$ a $10^{-3}$ e $10^{-4}$ pelas sucessivas transferências de $1,0 \mathrm{ml}$ em suspensão e inoculado em meio seletivo, "Agar Dextrose Saboraud"- Oxoid, por um período de $72 \mathrm{~h}$. 
As colônias viáveis foram isoladas e inoculadas em microcultivo para promover o crescimento reprodutivo, utilizando uma lâmina tipo "V", em um quadrante de $2 \mathrm{~cm}$ e incubadas a uma temperatura de $28^{\circ} \mathrm{C}$ a $30^{\circ} \mathrm{C}$ por $72 \mathrm{~h}$. A leitura foi observada em azul de algodão de lactofenol, utilizando um microscópico com aumento de 40 e 100X, tal procedimento foi utilizado para caracterizar os aspectos morfológicos do A. flavus e $A$. fumigattus nas amostras (Figura 1).

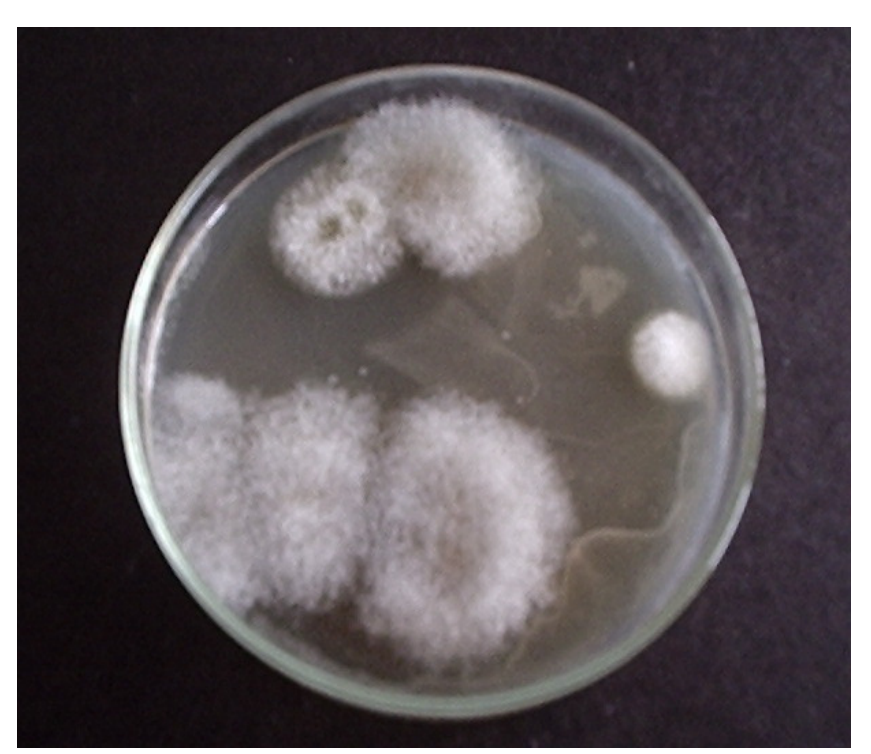

FIGURA 1: Visualização macroscópica: crescimento do Aspergillus spp. em placa (formação de hifas). Fonte: arquivo pessoal.

\section{Resultados e Discussão}

A amostra 1, proveniente do mercado municipal, obteve $100 \%$ de positividade em contaminação por $A$. flavus e A. fumigatus.

A amostra 2, proveniente de um hipermercado, deteve $75 \%$ de sementes contaminadas por A. flavus e A. fumigatus. Segundo Dhingra (1985), o processo de infecção inicia quando as sementes estão em equilíbrio com a umidade relativa em pelo menos $79 \%$. O desenvolvimento da infecção é determinado pela temperatura da semente, caracterizado pelo equilíbrio entre $25^{\circ} \mathrm{C}$ a $35^{\circ} \mathrm{C}$. Os efeitos iniciais da contaminação por Aspergillus spp. sobre as sementes de girassol são definidos pelo enfraquecimento do embrião seguido de sua morte.
A análise realizada na amostra 3, também oriunda de um hipermercado, obteve $100 \%$ de negatividade em todas as diluições. Podemos relacionar alguns fatores para o não desenvolvimento dos microrganismos: a rigorosidade das "Boas práticas de Fabricação" e o monitoramento adequado dos processos finais de industrialização.

Apesar do resultado encontrado na amostra 3, esteja de acordo com a Portaria no 065,16 fevereiro de 1993 do Ministério da Agricultura e do Abastecimento, sabe-se ainda da inexistência de uma legislação que padronize níveis de contaminação satisfatórios para comercialização de girassol.

Na amostra 4, também coletada de um hipermercado, foi constatada $75 \%$ de contaminação por $A$. flavus e $A$. fumigattus, ratificando a possibilidade do processamento e estocagem como fator de desenvolvimento de microrganismos. Este resultado corrobora aqueles encontrados por Bullerman et al., (1984); Watson, (1987); Coulombe, (1991); Frisvad e Samson, (1992) e Scussel, (1998) que a alta contaminação por Aspergillus spp., que indicam a contaminação estar relacionada a vários fatores, dentre eles a temperatura e a alta umidade relativa do ar.

Pesquisas realizadas por Lopez e Christensen (1967) citado por Dringa (1985) utilizaram sementes armazenadas sementes de milho com $19 \%$ de umidade a $20-25^{\circ} \mathrm{C}$. Uma parte das amostras foi inoculada $\operatorname{com} A$. flavus e a outra permaneceu livre do fungo. Após 74 dias as amostras "sadias" mantiveram sua germinação em $97 \%$ e as inoculadas com A. flavus apresentaram somente $14 \%$ de germinação. Os outros autores demonstrando, desta forma, que mesmo em condições adversas o $A$. flavus é capaz de se reproduzir em sementes sadias.

Foi observado, no experimento de Benez (2001) realizado em aves, um crescimento de A. flavus em materiais coletados da saliva, faringe, traquéia e seios nasais de indivíduos sadios, significando que o contato de alimentos a base de sementes e cereais contaminados faz com que a ave inale diariamente os esporos do fungo liberados pelas mesmas.

De acordo com a pesquisa aqui realizada foi possível observar um elevado desenvolvimento de 
A. flavus e A. fumigattus nas sementes de girassol. Esta contaminação pode estar relacionada a vários fatores: colheita e, fases de secagem, beneficiamento e armazenamento do grão inadequado. Além disso, é importante que haja um melhor armazenamento de grãos, com controle de temperatura e umidade relativa, visando reduzir prejuízos na alimentação de psitacídeos em decorrência da contaminação de Aspergillus spp., bem como de outras espécies domésticas de interesse econômico.

Fatores como adoção de medidas errôneas quanto ao manejo alimentar de psitacídeos, favorece ao estresse e, por conseguinte à deficiência do seu sistema imunológico, causando uma maior vulnerabilidade no surgimento da aspergilose.

Desta forma, a disseminação das informações obtidas nesta pesquisa torna-se importante para consultas, análise crítica e referência para o estudo e para a clínica sobre a alimentação de animais silvestres em cativeiro.

\section{Referências}

Andreatti Filho, R. L. 2006. Doenças fúngicas. In: Andreatti Filho, R. L. (Ed.). Saúde aviária e doenças. Roca, São Paulo, Brasil, p.236-245

Benez, S. M. 2001. Aves: Criação, clínica, teoria, prática, silvestres, ornamentais, avinhados. $3^{\text {a }}$ ed. Robe, São Paulo, Brasil, 522pp.

Bullerman, L. B.; Schroeder, L. L.; Park, K. Y. 1984. Formation and control of mycotoxins in food. Journal of Food Protection, 47 (8): 637-646.

Campbell, T. W. 1896. Bacterial diseases. In: Harrison, G. J \& Harrison, L. R. (Eds). Clinical avian medicine and surgery. W. B. Saunders Company, Philadelphia, USA, p.464-471.
Coulombe, R. A. 1991. Aflatoxins. In: Sharma R. P. \& Salunkhe, D. K. (Eds). Mycotoxins and Phytoalexins. CRC Press, London, UK, p.103-144.

Dhingra, O. O. 1985. Prejuízos causados por microorganismos durante o armazenamento de sementes. Revista Brasileira de Sementes, 7 (1): 139-146.

Diniz, S. P. S. S. 2002. Micotoxinas. Livraria e Editora Rural, Campinas, Brasil, 181pp.

Forsythe, S. J. 2002. Microbiologia da Segurança Alimentar. Ed. Artmed, Porto Alegre, Brasil, 424pp.

Frisvad, J. C.; Samson, R. A. 1992. Filamentous in foods and feeds: Ecology, spoilage, and mycotoxin production. In: Bhatnagar, D.; Lillehoj, E. B. \& Arari, D. K. (Eds). Handbook of applied mycology: "Mycotoxins in ecological systems". v.5. Marcel Dekker, New York, USA, p.32-57.

Junior, F. F. 2001. O uso do girassol na Psitacultura. Revista Atualidades Ornitológicas, 101: 10.

Lavour, C. T. B; Sousa, F. M. 2008. Micotoxicose em avestruz (Struthio camelus)-Relato de caso. Revista Ciência Agronômica, 39 (2): 348-352.

Ministério da Agricultura e do Abastecimento. 1993. Norma de identidade, qualidade, embalagem, marcação e apresentação do girassol. Portaria 063, de 16 de Fevereiro de 1993. Disponível em $<$ www.extranet.agricultura.gov.br $>$. Acesso em 30 de janeiro de 2010.

Richard, J. L. 1997. Fungal infections. In: Calnek, B. W.; Barnes, H. J.; Beard, C. W.; Reid, W. M. \& Yoder Junior, H. W. (Eds). Diseases of poultry. Iowa State University Press, Ames, USA, p.351-360.

Scussel, V. M. 1998. Micotoxinas em alimentos. Ed. Insular, Florianópolis, Brasil, p.19-22.

Tanaka, M. A. S.; Maeda, J. A.; Plazas, I. H. A. Z. 2001. Microflora fúngica de sementes de milho em ambientes de armazenamento. Scientia Agricola, 58 (3): 501-508.

Tovar, D. S. 199. Medicina de aves rapaces diurnas, Parte 2 Enfermidades infecciosas. Disponível em $<\mathrm{http} / / \mathrm{www}$.damisela. com/zoo/ave/otros/falcon>. Acesso em 25 de março de 2009.

Watson, D. H. 1987. Natural toxicants in food. Ellis Horwood, Chichester, UK, p.232-247. 